\title{
Cost-effectiveness of $\mathrm{Xpert}^{\oplus} \mathrm{MTB} / \mathrm{RIF}$ in the diagnosis of tuberculosis: pragmatic study
}

\author{
Suely Conceição Alves da Silva ${ }^{[1]}$, Maria Claudia Vater ${ }^{[1],[2], ~ D a n i e l a ~ M a r i a ~ d e ~ P a u l a ~ R a m a l h o ~}{ }^{[1],}$ \\ Isabela Neves de Almeida ${ }^{[3],[4]}$, Silvana Spíndola de Miranda ${ }^{[3]}$ and Afrânio Kritski ${ }^{[1]}$
}

\author{
[1]. Universidade Federal do Rio de Janeiro, Programa Acadêmico de Tuberculose, Rio de Janeiro, RJ, Brasil. \\ [2]. Universidade Federal do Rio de Janeiro, Núcleo de Bioética e Ética Aplicada, Rio de Janeiro, RJ, Brasil. \\ [3]. Universidade Federal de Minas Gerais, Faculdade de Medicina, Laboratório de Pesquisa em Micobactérias, \\ Departamento de Clínica Médica, Belo Horizonte, MG, Brasil.
}

[4]. Universidade Federal de Ouro Preto, Escola de Farmácia, Departamento de Análises Clínicas, Ouro Preto, MG, Brasil

\begin{abstract}
Introduction: The intensification of research and innovation with the creation of networks of rapid and effective molecular tests as strategies for the end of tuberculosis are essential to avoid late diagnosis and for the eradication of the disease. We aimed to evaluate the cost-effectiveness of Xpert ${ }^{\mathbb{}} \mathrm{MTB} / \mathrm{RIF}$ (Xpert) in the diagnosis of drug-resistant tuberculosis in reference units, in scenarios with and without subsidies, and the respective cost adjustment for today. Methods: The analyses were performed considering as criterion of effectiveness, negative culture or clinical improvement in the sixth month of follow-up. The comparison was performed using two diagnostic strategies for the drug susceptibility test (DST), Bactec ${ }^{\mathrm{TM} M G I T^{\mathrm{TM}}} 960$ System, versus Xpert. The cost effectiveness and incremental cost-effectiveness ratio (ICER) were calculated and dollar-corrected for American inflation (US\$1.00 = R \$ 5,29). Results: Subsidized Xpert had the lowest cost of US\$33.48 (R \$67,52) and the highest incremental average efficiency (13.57), thus being a dominated analysis. After the inflation was calculated, the mean cost was DST-MGIT $=$ US $\$ 74.85(\mathrm{R} \$ 396,73)$ and Xpert = US\$ $37.33(\mathrm{R} \$ 197,86)$ with subsidies. Conclusions: The Xpert in the diagnosis of TB-DR in these reference units was cost-effective with subsidies. In the absence of a subsidy, Xpert in TB-DR is not characterized as cost effective. This factor reveals the vulnerability of countries dependent on international organizations' subsidy policies.
\end{abstract}

Keywords: Multidrug-resistant tuberculosis. Cost-effectiveness. New diagnostics. Xpert MTB/RIF. Innovation.

\section{INTRODUCTION}

It is estimated that in 2018 , there were 10 million new cases of tuberculosis (TB), causing the death of about 1.5 million individuals ${ }^{1}$ and the same year, 72.788 new cases of the disease were reported in Brazil, of which 4.534 died of TB².

Since 2014, the Unified Health System (UHS) incorporated Xpert ${ }^{\mathbb{}}$ MTB/RIF (Xpert) in Brazil, after a pilot study carried out in Rio de Janeiro and Manaus ${ }^{3}$. With the incorporation of Xpert, there was no greater access or greater detection of cases of pulmonary $\mathrm{TB}^{4}$. Although the federal government has made the molecular test available since 2014, it does not have full coverage in the country.

\footnotetext{
Corresponding author: Profa. Silvana Spíndola de Miranda.

e-mail: silvanaspindola@gmail.com

(D) https://orcid.org/0000-0001-7245-4472

Received 22 October 2020

Accepted 15 January 2021
}

In addition, with the adoption of the molecular test, no drop in the proportion of abandonment or mortality was observed ${ }^{2}$.

The intensification of research and innovation with the creation of networks of rapid and effective molecular tests as strategies for the end of TB is essential to avoid the late diagnosis that hinders the control and eradication of the disease ${ }^{5}$. However, the process of incorporating rapid molecular tests subsidized for countries with high disease burden endorsed by the WHO for TB diagnosis is controversial ${ }^{6-9}$, as its incorporation has had a limited impact on health systems, in epidemiological indicators, and the interruption of the transmission chain 7 . This study evaluated the cost effectiveness of Xpert in reference units, in scenarios with and without subsidies and the respective cost adjustment for today, using primary cost data collected during a pragmatic clinical trial.

\section{METHODS}

It is a study of cost effectiveness evaluation of the Xpert test from secondary data on clinical effectiveness available in the literature ${ }^{10}$ 
and from the analysis of the PROVE IT project database, which allowed the systematization of unpublished cost data from the pragmatic clinical trial.

\section{Randomized pragmatic clinical trial - PROVE IT}

PROVE IT was a study developed in two stages: (1) Baseline, from October 2011 to July 2012, when routine clinical, laboratory, and therapeutic data were collected at each location; (2) Intervention, from August 2012 to May 2013, in which the new molecular tests were incorporated into the routine of each location. All patients were followed for six months by five State and / or National Reference Centers, in four Brazilian states (Rio de Janeiro, Sao Paulo, Ceara and Rio Grande do Sul), for the diagnosis and treatment of DR-TB. For randomization, the Stata software was responsible for allocating units and new technologies (Xpert and Genotype), defining two research branches to ensure each comparative analysis of each study arm: Arm 1: two Health Units used first-line drug susceptibility testing (DST) by Bactec ${ }^{\mathrm{TM}}$ MGIT $^{\mathrm{TM}} 960$ System (DST-MGIT) and Xpert; and Arm 2: three units used LPA and MGIT. In this study, only Arm 1 was addressed.

\section{Study Population}

Eligible patients were aged 18 years or older, presumed DR-TB with one or more of the following conditions: a) failure of previous treatment, b) contacts of DR-TB patients, c) people living with HIV, d) homeless and/or hospitalized, d) and who authorized their participation in the research signing a free and informed consent form.

\section{Laboratory Analysis}

Tests performed on clinical samples and cultures were performed in reference laboratories that follow the guidelines of the WHO and the National Tuberculosis Control Program of the Ministry of Health of Brazil ${ }^{11,12}$.

\section{Sampling}

After the first clinical visit, three moments of monitoring the collection of sputum samples for laboratory and culture analysis were described: 1) screening, 2) follow-up after two months, and 3 ) six months after the diagnosis was made. Follow-up was defined up to the sixth month, according to the treatment failure criterion for carrying out the DST-MGIT ${ }^{4}$. In this case, the participants were re-evaluated until this moment for the criteria that will be described below in data analysis. Data collection was performed in two reference units for the care of patients with drug-resistant Mycobacterium tuberculosis strains; the samples were sent to the Reference Laboratory and the results were released following the routine of each study site.

\section{Data Analysis}

The local research team collected information on the clinical, radiological, and laboratory evolution of the patients using standardized forms, from the clinical-laboratory area and the economic area of the Brazilian Tuberculosis Research Network [Rede Brasileira de Pesquisa em Tuberculose-REDE TB], adapted and used in PROVE IT. The statistical package IBM ${ }^{\circledR}$ SPSS for Windows version 20.0 was used for statistical analysis.

The analyses of this study were carried out with the results of the clinical trial ${ }^{10}$ : the proportion of patients who received empirical treatment who underwent DST-MGIT (97.7\%) and Xpert (45\%); the average time between screening and receiving the result of the intervention test by the doctor at DST-MGIT (73 days) and at Xpert (9.10 days); the average time between screening and the beginning of the correct treatment by DST-MGIT (57.7 days) and Xpert (26.8 days). A total of 53 patients were included in the DST-MGIT ( $\mathrm{n}=36)$ and Xpert $(\mathrm{n}=17)$, as a criterion of effectiveness: negative sputum result after the sixth month of follow-up $(n=20)$, of patients who underwent DST-MGIT; negative sputum result after the sixth month of treatment $(\mathrm{n}=10)$, of patients who underwent Xpert; favorable clinical and radiological results of patients who did not have sputum after the sixth month of follow-up of those who underwent DST-MGIT $(\mathrm{n}=9)$ and those who underwent Xpert (n $=6)$ at the beginning of treatment.

The follow-up of patients was performed by smear, culture, and DST-MGIT. Xpert was not performed in the follow-up to avoid false positive results.

\section{Economic Evaluation}

To perform the calculations, the costs related to the monthly expenses of each health unit directly associated with the activities necessary for the laboratory diagnosis of DR-TB were used, considering five cost components: equipment, human resources, supplies, infrastructure, and others (maintenance and loss of damage or misuse). The direct cost of DST-MGIT and Xpert was calculated to assess its impact on the UHS routine, through detailed cost chain modeling. This resulted in the measurement of the values of the following items: equipment (acquisition of equipment, considering the amortization of capital expenditure), human resources (salaries of human resources [source: UHS/Ministry of Planning, Development and Management - MPDG] dedicated to the production process related to the diagnostic approach to resistant TB or time spent in the activity and, in the case of non-exclusive dedication, to estimate the professional's remuneration), inputs (quantity of material to carry out consumption tests per year). Of the indirect costs, infrastructure (need to adapt the physical area, air-conditioned environment, electrical and third-party equipment, water, electricity, energy, and security) corresponded to the percentage spent on each item carried out by the set of activities involving TB in each health unit. The cost calculations of the new Xpert technology, since equipment and cartridges were not purchased at market price, considered the values "with subsidy" and "without subsidy" from the Foundation for Innovative New Diagnostics (FIND) $)^{10}$. The technique known as "mean cost" was the sum of the monthly expenses of all items used in the exam, divided by the number of exams performed in a month ${ }^{13}$.

For the cost-effectiveness analysis, a comparison of the two diagnostic strategies DST-MGIT versus Xpert for DR-TB was performed, considering the effectiveness of negative culture or clinical improvement in the sixth month of follow-up. 
To assess the impact of variations in both effectiveness and cost components, in the sensitivity analysis, we consider the confidence interval (IC 95\%) presented in the change of the initial conduct and the variation of $-50 \%$ to $+25 \%$ in the final value of the cost in each technology on the incremental cost-effectiveness ratio (ICER). ICER was defined as the result of the division between the difference in cost of new technologies and the difference in their effect [ICER $=$ $\left.\left(\mathrm{C}_{1}-\mathrm{C}_{2}\right) /\left(\mathrm{E}_{1}-\mathrm{E}_{2}\right)\right]$. where $\mathrm{C} 1=$ alternative cost $\mathrm{A}, \mathrm{C} 2=$ alternative $\operatorname{cost} \mathrm{B}, \mathrm{E} 1=$ effectiveness $\mathrm{A}$, and $\mathrm{E} 2=$ effectiveness $\mathrm{B}^{14}$.

The proportion of discount used was $5 \%$, according to the recommendations of the Methodological Guidelines for Studies of Economic Evaluation of Technologies for the Ministry of Health ${ }^{14}$.

The incremental cost of Xpert was calculated in two different scenarios: the first considering the value of equipment and cartridges at market prices (without subsidy), and the second with values subsidized by FIND/Diagnostic.

The inflation corrections in the country of origin and importing country were calculated according to the exchange rate variation of the commercial dollar in the period from 2012 to 2020, considering the inflation history for both countries (USA and Brazil) of the software reference for converting historical currencies and exchange rates, FXtop ${ }^{15}$.

\section{Sensitivity analysis of incremental effectiveness}

Sensitivity analysis was performed using the maximum and minimum values found in the clinical trial for both Xpert and DSTMGIT in the field of effectiveness. The sensitivity analysis was calculated as follows: in the first case, the average value of the DSTMGIT (80.55\%) was fixed, varying the XPERT to its maximum (99) and minimum (71) effectiveness, and in the case of Xpert (94.12\%), varying the DST-MGIT in its maximum effectiveness (91) and at least (65).

Regarding cost, two variables were used, with subsidy and without subsidy, dividing the values by the effectiveness according to the minimum and maximum variations, as described in the previous section.

This study used the variation in effectiveness as secondary data of the clinical study performed with the SPSS statistical package, version 20.0.

\section{Ethical Consideration}

The study was approved by the Ethics Advisory Group at the International Union Against Tuberculosis on May 10, 2011, EAG 11/11, and by the National Ethics Committee on September 29, 2011, register-1657, 2500.115789 / 2011-94.

\section{RESULTS}

\section{Cost-effectiveness Analysis}

The cost of DST-MGIT calculated using the mean cost method was US\$ 67.13. There is a large weight of inputs, representing $80.44 \%$ of the total cost (Table 1 and Supplement Material).

The mean cost of Xpert without subsidy and with subsidy was US\$ 175.24 and US\$33.48, respectively. In the composition of the total cost, the percentage of inputs was $87.58 \%$ without subsidy and $50.36 \%$ with subsidy (Table 1 and Supplement Material).

In Table 2, the cost effectiveness by Xpert technology, with subsidy had a value of US\$ 0.36 in relation to negative culture in the sixth month and the clinical improvement; the cost effectiveness without subsidy had a value of US\$ 1.86 (Supplement Material).

The incremental difference cost Xpert in relation to the o DSTMGIT was a strong dominance of Xpert, when calculating the value of the equipment and cartridges of the market price with subsidy, and the incremental effectiveness was 13.57 , which is a dominated analysis (Table 2 and Supplement Material).

The dollar correction for American inflation ${ }^{15}$ of the diagnostic tests shows in June 2020 the values of US\$ 74.85 (DST-MGIT), US\$ 37.33 (Xpert with subsidy) and US\$195.38 (Xpert without subsidy). Likewise, due to the correction of inflation, the incremental and ICER costs assume the values of US\$ 120.54 and US\$ 8.89, respectively (Table 3 and Supplement Material).

In the local currency, the MGIT amount went from R $\$ 135,39$ to $\mathrm{R} \$ 396,73$ and Xpert with a subsidy from $\mathrm{R} \$ 67,52$ to $\mathrm{R} \$ 197,86$ and Xpert without a subsidy from $R \$ 353,36$ to $R \$ 1.035,48$. Likewise, the incremental and ICER costs the Xpert without a subsidy from $\mathrm{R} \$ 218,00$ to $\mathrm{R} \$ 638,80$ and $\mathrm{R} \$ 16,07$ to $\mathrm{R} \$ 47,10$, respectively (Table 4 and Supplement Material).

TABLE 1: Mean cost of the Drug Susceptibility Test MGIT and Xpert ${ }^{\circledR} M T B / R I F$.

\begin{tabular}{|c|c|c|c|c|c|c|c|c|c|}
\hline \multirow[b]{2}{*}{ Cost Items } & \multicolumn{3}{|c|}{ DST-MGIT } & \multicolumn{3}{|c|}{ Xpert with subsidy } & \multicolumn{3}{|c|}{ Xpert without subsidy } \\
\hline & $\operatorname{MC}(\mathrm{R} \$)$ & MC(US\$) & $\%$ & $M C(R \$)$ & MC(US\$) & $\%$ & $\operatorname{MC}(\mathrm{R} \$)$ & MC(US\$) & $\%$ \\
\hline Equipment & 1,43 & 0.71 & 1.06 & 1,96 & 0.97 & 2.90 & 12,33 & 6.12 & 3.49 \\
\hline Human Resources & 24,21 & 11.99 & 17.88 & 29,70 & 14.73 & 43.99 & 29,70 & 14.74 & 8.40 \\
\hline Inputs & 108,91 & 54.01 & 80.44 & 34,0 & 16.86 & 50.36 & 309,47 & 153.46 & 87.58 \\
\hline Infrastructure & 0,84 & 0.42 & 0.62 & 1,86 & 0.92 & 2.75 & 1,86 & 0.92 & 0.53 \\
\hline Total & 135,39 & 67.13 & 100 & 67,52 & 33.48 & 100 & 353,36 & 175.24 & 100 \\
\hline
\end{tabular}

Legend: MC: Mean Cost; *American dollar on September 11, 2012, conversion value US $\$ 1.00=\mathrm{R} \$ 2,0165$; Xpert: Xpert ${ }^{\circledR} \mathrm{MTB} / \mathrm{RIF}$. 
TABLE 2: Cost effectiveness and Incremental Cost-Effectiveness Ratio.

\begin{tabular}{|c|c|c|c|c|c|c|}
\hline Diagnostic Test & $\begin{array}{l}\text { Mean Cost } \\
\quad \text { (US\$) }\end{array}$ & $\begin{array}{l}\text { Effectiveness } \\
\text { (negative culture } \\
\text { and clinical } \\
\text { improvement) }\end{array}$ & $\begin{array}{c}\text { Cost } \\
\text { Effectiveness } \\
\text { (US\$) }\end{array}$ & $\begin{array}{l}\text { Incremental } \\
\text { Effectiveness }\end{array}$ & $\begin{array}{l}\text { Incremental Cost } \\
\text { (US\$) }\end{array}$ & $\begin{array}{l}\text { ICER } \\
\text { (US\$) }\end{array}$ \\
\hline DST-MGIT & 67.13 & 80.55 & 0.83 & - & - & - \\
\hline Xpert with subsidy & 33.48 & 94.12 & 0.36 & 13.57 & dominated & dominated \\
\hline Xpert without subsidy & 175.24 & 94.12 & 1.86 & 13.57 & 108.11 & 7.97 \\
\hline
\end{tabular}

Legend: American dollar conversion value US $\$ 1.00=R \$ 2,0165$ on September 11, 2012. ICER: incremental cost-effectiveness ratio; DST: drug susceptibility test;

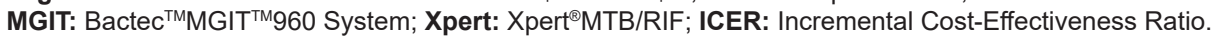

TABLE 3: Cost effectiveness and ICER dollar-corrected for American inflation*.

\begin{tabular}{cccccc}
\hline Diagnostic Test & $\begin{array}{c}\text { Mean Cost } \\
\text { (US\$) }\end{array}$ & Effectiveness** & $\begin{array}{c}\text { Cost } \\
\text { Effectiveness } \\
\text { (US\$) }\end{array}$ & $\begin{array}{c}\text { Incremental } \\
\text { Effectiveness }\end{array}$ & $\begin{array}{c}\text { Incremental Cost } \\
\text { (US\$) }\end{array}$ \\
\hline DST-MGIT & 74.85 & 80.55 & 0.93 & - & - \\
ICER (US\$) & dominated & 13.57 & 12.54 \\
Xpert with subsidy & 37.33 & 94.12 & 94.12 & 2.07 & 8.89 \\
\hline
\end{tabular}

Legend: *American inflation $=11.49 \%$ on period of $11 / 09 / 2012$ at 02/06/2020 in https://fxtop.com/pt/calculadora-de-inflacao.php; American dollar conversion value US\$1.00 = R \$ 5,2993 in June, 2 of 2020. ${ }^{*}$ Negative culture and clinical improvement. ICER: Incremental Cost-Effectiveness Ratio; DST: Drug Susceptibility Test;

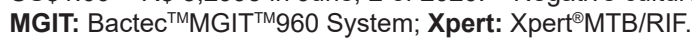

TABLE 4: Exchange variation - import $R \$ /$ Brazil.

\begin{tabular}{|c|c|c|c|c|c|}
\hline & $\begin{array}{l}\text { Test } 2012 \\
\text { (R\$/BRL) }\end{array}$ & American Inflation & $\begin{array}{l}\text { Test } 2020 \\
\text { (R\$/BRL) }\end{array}$ & $\begin{array}{c}\text { Exchange Rate } \\
\text { Variation }\end{array}$ & $\begin{array}{c}\text { Real Value } \\
2020(R \$ / B R L)\end{array}$ \\
\hline DTS-MGIT Cost & 135,39 & & 150,94 & & 396,73 \\
\hline Xpert with subsidy & 67,52 & & 75,28 & & 197,86 \\
\hline Xpert without subsidy & 353,36 & & 393,96 & & $1.035,48$ \\
\hline $\begin{array}{l}\text { Xpert Incremental cost } \\
\text { without subsidy }\end{array}$ & 218,00 & $11.49 \%$ & 243,04 & $162.84 \%$ & 638,80 \\
\hline $\begin{array}{l}\text { Xpert Cost } \\
\text { Effectiveness } \\
\text { Incremental } \\
\text { without subsidy }\end{array}$ & 16,07 & & 17,92 & & 47,10 \\
\hline
\end{tabular}

Legend: $11.49 \%=$ on period of 11/09/2012 at 02/06/2020 in https://fxtop.com/pt/calculadora-de-inflacao.php; American dollar on September 11, 2012, conversion

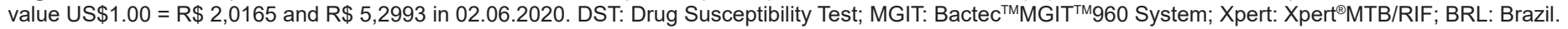

\section{Sensitivity analysis of incremental effectiveness}

The analysis of the increment in three situations: in the first, varying Xpert effectiveness within the values of $71 \%$ (minimum) and $99 \%$ (maximum), the negative value after six months was maintained at $80.55 \%$ for DST-MGIT; in the second, $94.12 \%$ negativity for Xpert was maintained and DST-MGIT negativity varied between $65 \%$ and $91 \%$, according to the values found. A value for negative culture or clinical improvement of Xpert of $71 \%$ was obtained, characterizing a scenario without incremental effectiveness; in the third, the variation was in cost when the value of Xpert without subsidy was used, with an average value of US\$175.24 (Table 5 and Supplement Material).

The values found when negative in the sixth month or clinical improvement of Xpert, assumes a minimum value of $71 \%$; therefore, it is a dominated analysis. In the case of the cost of Xpert without subsidy, the ICER was US\$ 7.97. When considering the $91 \%$ effectiveness for DTS-MGIT, ICER was US $\$ 34.65$ for six months' negative results and clinical improvement (Table 5 and Supplement Material). 
TABLE 5: Incremental effectiveness by variation Maximum and Minimum Xpert with subsidies and DST-MGIT.

\begin{tabular}{|c|c|c|c|c|}
\hline \multicolumn{5}{|c|}{ Xpert with Subsidies } \\
\hline & Xpert & Xpert & (variation) and DST-MGIT (fixed) $80.55 \%$ & \\
\hline Maximum & 99.00 & & 18.45 & \\
\hline Average & 94.12 & & 13.57 Incremental effectiveness & \\
\hline \multirow[t]{2}{*}{ Minimum } & 71.00 & & Negative (-9.55) & \\
\hline & DST-MGIT & \multicolumn{3}{|c|}{ DST-MGIT (variation) and Xpert (fixed) $94.12 \%$} \\
\hline Maximum & 91.00 & & 3.12 & \\
\hline Average & 80.55 & \multicolumn{3}{|c|}{13.57 Incremental effectiveness } \\
\hline Minimum & 65.00 & \multicolumn{3}{|c|}{29.12} \\
\hline $\begin{array}{c}\text { Xpert } \\
\text { Without subsidy }\end{array}$ & $\begin{array}{c}\text { Incremental cost } \\
\text { Xpert without subsidy less } \\
\text { DST-MGIT }\end{array}$ & \multicolumn{2}{|l|}{$\begin{array}{c}\text { Test's effectiveness } \\
\text { and Standard Deviation }\end{array}$} & ICER \\
\hline \multirow{6}{*}{ US\$ 175.24} & \multirow{6}{*}{ US\$108.11 } & Maximum 99.00 & \multirow{4}{*}{$\begin{array}{l}\text { Xpert (variation) and DST- } \\
\text { MGIT (fixed) }\end{array}$} & US\$ 5.85 \\
\hline & & Average 94.12 & & US\$ 7.97 \\
\hline & & Minimum 71.00 & & dominated \\
\hline & & Maximum 91.00 & & US\$ 34.65 \\
\hline & & Average 80.55 & \multirow{2}{*}{$\begin{array}{l}\text { DST-MGIT (variation) and } \\
\quad \text { Xpert (fixed) } 94.12 \%\end{array}$} & US\$ 7.97 \\
\hline & & Minimum 65.00 & & US\$ 3.71 \\
\hline
\end{tabular}

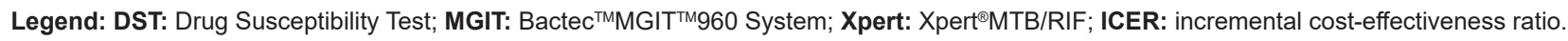

\section{DISCUSSION}

Xpert in subsidized conditions was more cost effective than DST-MGIT for incorporating the new technology in the routine diagnosis of DR-TB in the Brazilian UHS. In addition to the dependency condition (subsidy), the cost-effectiveness analysis showed that the cartridge used by the Xpert machine had the highest percentage in calculating the total cost of this technology. The percentage of the cartridge cost was $50.36 \%$ of the final cost in the test with subsidy and $87.58 \%$ without subsidy. This input, being imported, reinforces the vulnerability in a situation of exchange rate depreciation, which can bring economic limitations for the incorporation of technology into the national health system. Contingent factors of market relations and/or changes in the position of a developing country ${ }^{16}$ can lead to the main cost component (cartridge) of the test to assume the market value, ceasing to be cost-effective for the criterion of negativity in the sixth month and clinical improvement of DR-TB patients in the studied sites.

Xpert was cost effective when compared to DST-MGIT when analyzing sensitivity variation for both incremental effectiveness and incremental cost. In addition, it presented significant advantages with regard to the increase in TB detection and its satisfactory accuracy; however, there are controversies regarding its implementation in order to support decision making ${ }^{8,17}$. An investigation ${ }^{9}$ showed that the benefits expected from the rapid detection of Xpert were not reflected in the improvement of the patient throughout the treatment; consequently, the costs did not decrease, even with subsidized incentive policies in South Africa.
Similar results can be found in a study ${ }^{7}$ analyzing the limited impact of Xpert and its gaps in the ability to produce and maintain an effect for the patient, also observed ${ }^{17}$ when there was no significant difference in the proportions of cure among patients allocated to the Xpert group and the control group or, as shown in another study ${ }^{18}$ that, despite having found excellent accuracy, suggests additional studies aimed at the evaluation of the Xpert impact on the patient.

In a recent meta-analysis carried out by the Collaborative Group for the Meta-Analysis of Data of Individual Patients in the treatment of MDR TB, the "surprising" discovery of the lack of benefit of several drugs commonly prescribed for MDR TB treatment was highlighted $^{19}$.

In order to address the problem of the increase in DR/MDR/ XDR-TB, the race for molecular tests that are faster and more accurate in the diagnosis has been the object of permanent research in the world ${ }^{5,20,21}$. The Xpert system is an example of the global expansion of philanthropy characterized by the incorporation of technological innovation products in the healthcare market. The development of Xpert for TB control was subsidized by the Gates Foundation's 15 million USD investment in the Cepheid Company. FIND monitored contract expenditures for the development of the Xpert cartridge for US\$7.23 million and US\$1 million for the calibration kit required by the test $\mathrm{t}^{22}$. The remaining US $\$ 6.8$ million of the grant went to clinical trials and project management that enabled the partnership among industry, academia and governments in several countries ${ }^{22}$. 
From the point of view of the data found in this study, this kind of "philanthropic episteme" became necessary and important because it has the strength to show with transparency the birth of the innovation and research and development (R\&D) activities of the studied technology, and also to estimate the variability of the intersection point that involves the incorporation of subsidized technologies in low-and middle-income and dependent countries. Among the countries in South America that incorporated Xpert, Brazil continues to be the main customer in the acquisition of machines and cartridges ${ }^{23}$, as it is the largest public continental health system. In 2018, the Ministry of Health took the strategic decision to purchase more diagnostic equipment from the GeneXpert system, totaling the coverage of 135 municipalities with 249 machines $^{2,4}$.

The clinical decision made by doctors in prescribing tuberculosis treatment (empirical treatment) before test results was less for the group of patients at Xpert (65\% Xpert and 97\% DST-MGIT), which is in line with the statement of the potential of rapid tests to reduce empirical treatment and better control DR-TB. However, the finding of $65 \%$ of prescriptions for treatment of probability when having a test that presents sensitivity $82 \%$ to $93 \%$ and specificity $96 \%$ to $100 \%$, seems to reveal that under routine of the studied places the time between the laboratory result and the doctor's receipt of this does not correspond to the standard established by the technology provider $^{24,25}$.

An important contribution of this study and consistent in different cases $^{12}$ is that clinical trials in the routine of the units have significance for impact assessment and the incorporation of new diagnostic tests, due to the potential to demonstrate organizational problems in the local health system that make it difficult to receive the treatment properly and in the shortest time possible.

The dependence on new technology and exchange variation are factors that proved to be central in this cost analysis, which was also demonstrated in a study ${ }^{26}$ stating that subsidies should be considered in decision making in addition to other factors that, from a future perspective, they impact the real cost of a new test for dependent countries $^{26}$. When considering American inflation, between the years 2012 and $2020^{15}$, on the total cost of each diagnostic test, an increase in the ICER was observed from US\$ 7.97 to US\$ 8.89. These results, corrected by the US inflation accumulated in the period in the conversion of the current exchange rate to the importing country, generate the cost adjustment and make the new test no longer cost-effective, in relation to the other, which shows the "subsidized condition" as a vulnerability in incorporation in dependent countries: Xpert with subsidy R\$ 67,52 - US\$ 33.48 to R\$197,86 - US\$ 37.33, Xpert without subsidy R\$353,36 US\$ 175.24 to R\$ $1.035,48$-US\$ 195.38 and DST-MGIT $\mathrm{R} \$ 135,39-\mathrm{US} \$ 67.13$ to R $\$ 396,73$ - US\$ 74.85 .

These results call attention to the fact that added to the factor (inflation of the country of origin that produces the technology), it is also necessary to take into account the variation in the exchange rate of the American currency in the importing country (Brazil). Thus, the devaluation of the currency $(\mathrm{R} \$)$ has an effect on the increase in the exchange rate of the American currency, which results in the need for a larger amount of reais to purchase the same dollar unit. In this scenario, the budgetary impact in relation to the import of equipment and/or inputs can be catastrophic for the health system, even in a subsidized situation, reinforcing that subsidies must be taken into account in decision-making in peripheral countries.

The confidence that evidence is capable of inspiring for decision making, central to the evaluation of new diagnostic tests in $\mathrm{TB}^{21}$, finds the best investigative model in pragmatic clinical trials, as these occur in the routine of services, with patients who really depend on adequate treatment. Therefore, it is essential to consider that in the analysis of the accuracy and usefulness of a new technology, it must be subject to applicability in the "real life" of the local health system, in order to answer the questions of essential and sustainable adjustments in the treatment of DR-TB.

It was evident that the implementation of diagnostic tests in the routine showed a statistical difference in the favorable outcomes of the treatment of DR-TB $(\mathrm{p}=0.04)$ in patients whose clinical samples were submitted to Xpert compared to those submitted to DST-MGIT in the analyzed period. However, the difference between the cost-effectiveness results is reversed if the subsidy is withdrawn and, due to the cost adjustment for the current year, the subsidized test is not cost effective. The definition of prioritization criteria, considering the possible scenarios and the implicit risks of subsidized costs, to justify the decision to incorporate the new test in the UHS were not investigated in this study.

However, in the evidence-based deliberative process proposed in other studies ${ }^{25,27}$, there is a complexity in this path because the definition is the result of a political process loaded with value and divergences. Therefore, the cost evaluation will need to be weighed by the relative importance of the criteria for choosing those involved in the deliberation process. Furthermore, it has been highlighted that the dominant use of cost-effectiveness information for decisionmaking may not be the fairest choice for universal health systems. Finally, it is argued that the assessment of health technologies needs to make explicit the evidence-based deliberative process to facilitate learning among stakeholders.

In the decision-making for the subsidized incorporation of a new diagnostic test in the UHS, the analysis of the cost impact without Xpert subsidy does not seem to have prevailed. To contribute to the eradication of the disease, this choice could be weighted by the improvement in epidemiological indicators, which did not occur in this Brazilian scenario ${ }^{4,28,29}$.

This study had limitations regarding the small number of patients included in the clinical intervention stage and not having followed up the patients until the end of MDR-TB treatment, although it is representative of the reality of the routines of each participating health unit. Another limitation, since the completion of this study to the present day, there are technical variations in laboratory activity that have not been analyzed. Due to the clinical and laboratory peculiarities of each location, generalization of results is not allowed.

In conclusion, in the context of the data presented here, Xpert in the diagnosis of TB-DR in these reference units was cost effective. 
When corrected by the US \$ inflation accumulated in the period in the conversion of the current exchange rate to the importing country, generate the cost adjustment and make the new test no longer costeffective. For decision making by UHS managers, there is still a great challenge due to the complexity of the Brazilian health system, which requires more pragmatic clinical trials. In addition, in cases where the technology has a large weight of imported items, attention should be paid to factors such as the local exchange rate and inflation in the country where the technology is produced, which should be included in the economic assessment of the incorporation of new methods of diagnosis in resistant tuberculosis.

\section{ACKNOWLEDGEMENTS}

The authors wish to thanks the National Council for Scientific and Technological Development (CNPq) Rio de Janeiro State Research Support Foundation (FAPERJ), Federal University of Rio de Janeiro and The Brazilian Tuberculosis Network Research (REDE-TB).

\section{FINANCIAL SUPPORT}

PROVE IT/TREAT TB: Technology, Research, Education and Technical, Assistance for Tuberculosis. No: USAID-M-OAAGH-08-923. This work was supported by the National Council for Scientific and Technological Development (CNPq) by means of Process: 559081/2009-0-Decit/MS-CNPq; Rio de Janeiro State Research Support Foundation (FAPERJ) by means of Process: ${ }^{\circ}$ E: 26/111608/2008. Dr Isabela Almeida, received founds for this work under the pos-doc schollarship - Process - CNPq /INCT 465318/2014-2.

\section{AUTHORS' CONTRIBUTION}

SCAS: Conception and design of the study, Acquisition of data, Analysis and interpretation of data, design the methodology of the study, validation of data, Drafting the article, Final approval of the version to be submitted; MCV: Conception and design of the study, Lead the data curation, Analysis and interpretation of data, design the methodology of the study, validation of data, supervision and administration of the project, Drafting the article, Final approval of the version to be submitted; DMPR: Conception and design of the study, Acquisition of data, Analysis and interpretation of data, design the methodology of the study, validation of data, Drafting the article, Final approval of the version to be submitted; INA: Analysis and interpretation of data, supporting on design the methodology of the study, validation of data, Drafting the article, Final approval of the version to be submitted; SSM: Analysis and interpretation of data, supporting on design the methodology of the study, validation of data, Drafting the article, Final approval of the version to be submitted; ALK: Conception and design of the study, Lead the data curation, Lead the Funding acquisition, Analysis and interpretation of data, design the methodology of the study, validation of data, supervision and administration of the project, Drafting the article, Final approval of the version to be submitted.

\section{CONFLICT OF INTEREST}

The authors declare that there is no conflict of interest.

\section{REFERENCES}

1. World Health Organization (WHO). Global tuberculosis report 2019. Geneva: WHO; 2019. 194p.

2. Ministério da Saúde (MS), Secretaria de Vigilância em Saúde. Boletim Epidemiológico 09. Brasília: MS; 2019. 3p.

3. Durovni B, Saraceni V, van den Hof S, Trajman A, Santos MC, Cavalcante $\mathrm{S}$, et al. Impact of replacing smear microscopy with Xpert MTB/RIF for diagnosing tuberculosis in Brazil: a stepped-wedge cluster-randomized trial. PLoS Med. 2014;11:e1001766.

4. Ministério da Saúde (MS). Secretaria de Vigilância em Saúde Manual de Recomendações para o Controle da Tuberculose no Brasil. Departamento de Vigilância das Doenças Transmissíveis. Brasília: MS; 2019. 55-63p.

5. Kritski A, Dalcolmo MP, Mello FCQ, Carvalho ACC, Silva DR, Oliveira MM, et al. O papel da Rede Brasileira de Pesquisas em Tuberculose nos esforços nacionais e internacionais para a eliminação da tuberculose. J Bras Pneumol. 2018;44(2):77-81.

6. Creswell J, Codlin AJ, Andre E, Micek MA, Bedru A, Carter EJ, et al. Results from early programmatic implementation of Xpert MTB/RIF testing in nine countries. BMC Infect Dis. 2014;14:2.

7. Albert H, Nathavitharana RR, Isaacs C, Pai M, Denkinger CM, Boehme $\mathrm{CC}$, et al. Development, roll-out and impact of Xpert MTB/RIF for tuberculosis: what lessons have we learnt and how can we do better? Eur Respir J. 2016;48(2):516-25.

8. Naidoo P, Dunbar R, Lombard C, du Toit E, Caldwell J, Detjen A, et al. Comparing tuberculosis diagnostic yield in smear/culture and Xpert ${ }^{\circledR}$ MTB/RIF-based algorithms using a non-randomised steppedwedge design. PLoS One. 2016;11(3):e0150487.

9. Vassall A, Siapka M, Foster N, Cunnama L, Ramma L, Fielding K et al. Cost-effectiveness of Xpert MTB/RIF for tuberculosis diagnosis in South Africa: a real-world cost analysis and economic evaluation. Lancet Glob Health. 2017;5(7):e710-e719.

10. Ramalho DMP, Miranda PFC, Andrade MK, Brígido T, Dalcolmo MP, Mesquita E, et al. Outcomes from patients with presumed drug resistant tuberculosis in five reference centers in Brazil. BMC Infect Dis. 2017;17(1):571

11. Ministério da Saúde (MS). Secretaria de Vigilância em Saúde. Manual nacional de vigilância laboratorial da tuberculose e outras micobactérias. Brasília: MS; 2010. 190 p.12.

12. World Health Organization (WHO). Automated Real-Time Nucleic Acid Amplification Technology for Rapid and Simultaneous Detection of Tuberculosis and Drug Resistant Tuberculosis: Policy Statement. Geneva: WHO; 2013. 10 p.

13. Ministério da Saúde (MS), Secretaria de Ciência, Tecnologia e Insumos Estratégicos, Departamento de Economia e Saúde. Manual Técnico de Custos - Conceitos e Metodologias. Brasília: MS; 2006. 13p.

14. Ministério da Saúde (MS), Secretaria de Ciência, Tecnologia e Insumos Estratégicos, Departamento de Ciência e Tecnologia. Diretrizes metodológicas: Sistema GRADE. Manual de graduação da qualidade da evidência e força de recomendação para tomada de decisão em saúde. Brasília: MS; 2014. 28 p.

15. Bureau of Labor Statistics. Cálculo da inflação entre 2 datas após 1901 e gráfico [Internet]. Estados Unidos, 2020 [updated 2020 September 19; cited 2020 Oct 17]. Available from: https://bitlybr.com/YKBfJXr.

16. Fiori JL. História, estratégia e desenvolvimento: para uma geopolítica do capitalismo. 1th ed. São Paulo: Boitempo; 2015. 22p.

17. Padayatchi N, Naidu N, Yende-Zuma N, O'Donnell MR, Naidoo K, Stanton $\mathrm{A}$, et al. Implementation and operational research: clinical 
impact of the Xpert MTB/RIF assay in patients with multidrug-resistant tuberculosis. JAIDS. 2016;73(1):e1-e7.

18. Silva TM, Soares VM, Ramos MG, Santos A. Acurácia do teste rápido molecular para tuberculose em amostras de escarro, lavado broncoalveolar e aspirado traqueal obtidos de pacientes com suspeita de tuberculose pulmonar em um hospital de referência terciária. J Bras Pneumol. 2019;45(2):e20170451.

19. Horne DJ, Kohli M, Zifodya JS, Schiller I, Dendukuri N, Tollefson D, et al. Xpert ${ }^{\mathbb{B}} \mathrm{MTB} / \mathrm{RIF}$ and Xpert ${ }^{\mathbb{\mathbb { B }}} \mathrm{MTB} / \mathrm{RIF}$ Ultra for pulmonary tuberculosis and rifampicin resistance in adults. Cochrane Database Syst Ver. 2019; 6:CD00959339.

20. World Health Organization (WHO). Global Tuberculosis Report 2013. Geneva: WHO; 2013. 46p.

21. Huf G, Kritski A. Evaluation of the clinical utility of new diagnostic tests for tuberculosis: the role of pragmatic clinical trials. J Bras Pneumol. 2012;38(2):237-45.

22. Bill \& Melinda Gates Foundation. Public-Private Partnership Announces Immediate 40 Percent Cost Reduction for Rapid TB [Internet]. Gates Foudation USA; 2012 [updated 2012 September 19; cited 2020 Oct 17]. Available from: https://www.gatesfoundation. org/Media-Center/PressReleases/2012/08/PublicPrivate-PartnershipAnnounces Immediate-40-Percent-Cost-Reduction-for-Rapid-TB-Test.

23. World Health Organization (WHO). WHO monitoring of Xpert ${ }^{\mathbb{}}$ MTB/ RIF roll-out: Procurements of GeneXperts and Xpert ${ }^{\mathbb{R}} \mathrm{MTB} / \mathrm{RIF}$ cartridges [Internet]. WHO Geneva; 2020 [updated 2020 September 19; cited 2020 Oct 17]. Available from: https://www.who.int/tb/areas-ofwork/laboratory/mtb-rif-rollout/en/.

24. CepheidC. Xpert MTB/RIF Data Sheet [Internet]. Cepheid USA; 2020 [updated 2020 September 19; cited 2020 Oct 17]. Available from: https://www.cepheid.com/en_US/tests/Critical-Infectious-Diseases/ Xpert-MTB-RIF.

25. Baltussen R, Jansen MP, Mikkelsen E, Tromp N, Hontelez J, Bijlmakers $\mathrm{L}$, et al. Priority setting for universal health coverage: we need evidence-informed deliberative processes, not just more evidence on cost-effectiveness. Int J Health Policy Manag. 2016;5(11):615-18.

26. Boehme CC, Nabeta P, Hillemann D, Nicol MP, Shenai S, Krapp F, et al. Rapid molecular detection of tuberculosis and rifampin resistance. $\mathrm{N}$ Engl J Med. 2010;363:1005-15.

27. Kapiriri L, Baltussen R, Oortwijn W. Implementing evidence-informed deliberative processes in health technology assessment: a low income country perspective. Int J Technol Assess. 2020;36(1):29-33.

28. Di Tanna GL, Khaki AR, Theron G, McCarthy K, Cox H, Mupfumi $\mathrm{L}$, et al. Effect of Xpert MTB/RIF on clinical outcomes in routine care settings: individual patient data meta-analysis. Lancet Glob Health. 2019;7(2):e191-e199.

29. Ministério da Saúde (MS). Secretaria de Vigilância em Saúde, Departamento de Vigilância das Doenças Transmissíveis. Panorama da tuberculose no Brasil: diagnóstico situacional a partir de indicadores epidemiológicos e operacionais. Brasília: MS; 2018. 28 p. 